THE CEO'S BOSS 



\section{WILLIAM M. KLEPPER}
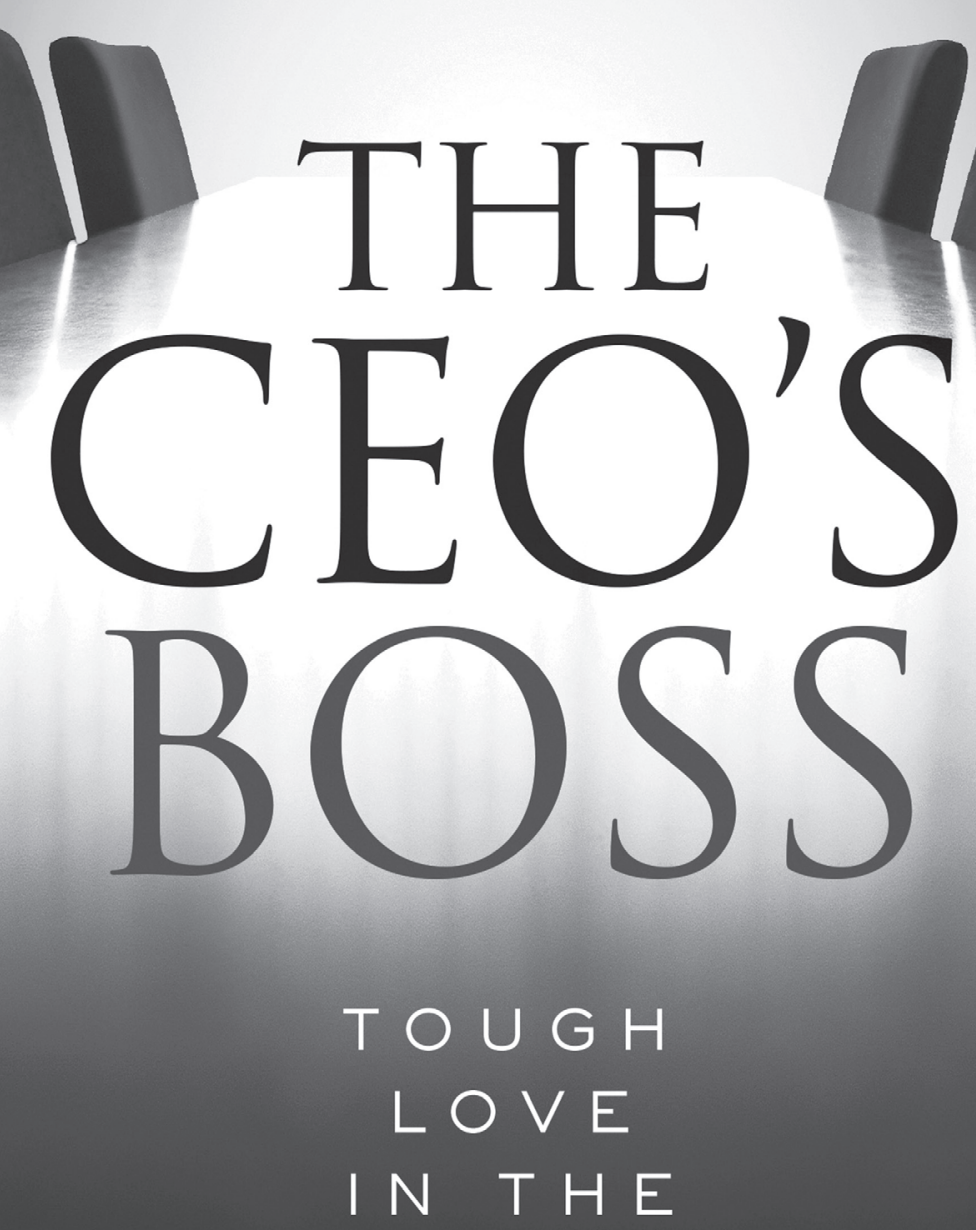

$B O A R D R O O M$

$$
\text { 2ND EDITION }
$$

\section{$4 \underset{\text { Cublishing }}{\text { Columbia Business School }}$}


Columbia University Press

Publishers Since 1893

New York Chichester, West Sussex

cup.columbia.edu

Copyright (C) 2019, 2010 Columbia University Press

All rights reserved

Library of Congress Cataloging-in-Publication Data

Names: Klepper, William M., author.

Title: The CEO's boss : tough love in the boardroom / William M. Klepper. Description: 2nd edition. | New York : Columbia University Press, [2019] |

Includes bibliographical references and index.

Identifiers: LCCN 2018029223 (print) | LCCN 2018031446 (e-book) |

ISBN 9780231547307 (e-book) | ISBN 9780231187503 (cloth: alk. paper)

Subjects: LCSH: Chief executive officers. | Corporate governance.

| Decision making. | Leadership.

Classification: LCC HD38.2 (e-book) | LCC HD38.2 .K58 2019 (print) |

DDC 658.4/22-dc23

LC record available at https://lccn.loc.gov/2018029223

Columbia University Press books are printed on permanent and durable acid-free paper.

Printed in the United States of America

Cover image: @ George Doyle/Stockbyte/Getty Images 